\title{
Web Portal Analysis of Asian Region Countries
}

\author{
Subhash Chander \\ Govt. P.G. College,Sec-14, Karnal (Haryana), India \\ Email:subhashjaglan@gmail.com \\ Ashwani Kush \\ University College, Kurukshatra University, Kurukshetra (Haryana), India \\ Email:akush20@gmail.com
}

\begin{abstract}
The number of online services provided by Government and private sectors is increasing these days. On the same pattern various countries have their own portals to provide basic services to the citizens and other people of the world. Analysis of portals in Asia is the main theme of the paper. There are various indicators or attributes necessary for the implementation of e-services .Some of the indicators may be frequency of use of services, number of users, visitors, site hits, searchable option, accessibility, language option, performance, functionality, broken links, traffic analysis, and feedback. Out of these metrics taken into consideration here are Traffic analysis, feedback, accessibility, security and language option. The countries taken into consideration are India, China and Pakistan. Web portals of these countries will be analyzed in detail.
\end{abstract}

Index Terms - E-Governance, E-services, security, ICT, E-government, web portal, Citizen Participation

\section{INTRODUCTION}

The dawn of the Information Technology (IT) age and rapid growth of Internet have led to every sector whether Private or Government computerizing their services for its citizens throughout the world. This phenomenon of computerizing services is broadly referred to as e-government. E-government, the application of ICT within public administration to optimize its internal and external functions, provides government, the citizens and business with a set of tools that can potentially transform the way in which interactions take place, services are delivered, and citizens participate in governance [3]. In the past various technological developments like Radio, T.V, computer and video conferencing have played important role in the development of the country. People have reaped the benefits of these technologies a lot. Today it is the turn of Information and communication Technology (ICT) and Internet. Expectation of citizens has increased a lot in the modern world of ICT. This expectation creates pressure on governments to perform.
E-governance initiatives are results of such pressures by citizens combined with the capabilities achieved through the use of ICT. The potential of web portals in reaching out to citizen users can not be denied at all. One of the important aspects of e-governance is the use of government web portals as an electronic medium for government to Citizens' (G2C) interactions. There is a need to understand e-governance users' perceptions, specifically, what constitutes a high quality e-governance online service quality [4]. In the past, web portals have not often been used and associated with citizen demands. ICT for Governance has not been used properly by the governments. Government and governance are used for getting the consent and cooperation of the governed. Government is the formal apparatus for this objective and Governance is the outcome as experienced by those on the receiving end. Government is an institutional superstructure that society uses to translate politics into policies and legislation. Governance is the outcome of interaction of government, the public service, and citizens throughout the political process, Policy development, program design, and service delivery [2]. Governments contribute to governance. Democratic Governments seek and receive citizen support and active cooperation of public servants. Modernization of public services based on the power of Information and Communication Technology (ICT) has given birth to new type of Governance named as e-Government. E-Government is the name given to use of electronic means to deliver and provide effective and efficient Government. E-Government is much secure, provide quality services, citizen engagement, financial benefits for Government and citizens as compared to traditional Government. The potential benefit of e-government to citizens, business and public administration include user can interact with Government through Kiosk, Internet and mobile devices [1]. E-government is not simply an introduction to web-based technologies but a complex social system which covers key social issues. It provides opportunities for the government to reconsider how and in what way to deliver better public services to meet users' needs .E-Government and E-Governance are used interchangeably many times yet there are certain 
differences between the two. E-Government is more fruitful and productive as compared to traditional Government. But problems here are of the implementation and Management. E-Governance can happen to be participatory Governance if it is well supported and architected [2]. Various challenges in e-Governance are resistance from those who want to have the system of Governance as it is and thinking of the citizens about bureaucrats regarding implementation of various policies and rules with sincerity. Yet there are chances of failures of various e-governance projects in developing countries due to such challenges. Only $15 \%$ of the total projects of e-governance are complete success whereas $50 \%$ are partial failure and $35 \%$ are totally failure [5]. Section 2 shows related work, section 3 gives details of choice of portals, section 4 gives analysis of portals and section 5 gives conclusion of the paper.

\section{RELATED WORK}

ICT has already shown its potential in increasing the productivity and effectiveness of organizations. Government's anti-corruption drive can also be boosted through e-governance because it will bring openness and transparency in government affairs. Every ministry and division must be asked to register information about their procurements and other affairs at the government portal by the use of e-governance. That will certainly help in the diminishing corruption spread among various countries. The ultimate test is whether governments can use e-governance as a technology to operate more efficiently, to design and implement better policies, and to provide programs and services more effectively [6]. Study [3] ranked municipalities worldwide based on their scores in five e-governance categories of security and privacy, usability, content, services and citizen participation. Essentially, the web portal is the new face of government, and steps need to be taken to ensure that the relationship between government and citizens is maintained, if not enhanced, by the transformation to e-government [3]. Since E-Governance services are to be provided by the Government hence Quality in providing service will increase user satisfaction and services would be realized by more and more citizens. Various evaluation parameters are taken into account for performance evaluation of e-Governance web portals by many authors. Unit Research report [4] brings out other important attributes as ready access to information, wide range of services by single website, ease of contact by users, integrated services, assurance factors, interaction using multiple means, website design, privacy and security concerns. Another study [16] takes into account the metrics like e-readiness, accessibility, use of information on web portal, look of portal, services ,reliability, size and complete information language and server side analysis for evaluating the e-governance web portals of two countries. Also there may be a long list of such parameters but basically core parameters for evaluation purpose must be taken into account. Security component is also one of the major factor which determines the success or failure of any web portal. But security measurement is typical issue and requires certain permissions from government officials and designers of these portals which is again a tedious process. Privacy of the information about citizens is also the top priority of any Government. Hence Privacy and security is also taken into account for these portals. Conclusively metrics like content, usability, accessibility, privacy \& security, General services (including search, user awareness movements, feedback \& language) citizen participation and visitors summary have been taken into account for the evaluation of the selected Asian countries.

\section{CHOICE OF PORTALS}

Information delivery is regarded as one of the most important role of e-governance initiatives. In the last few years many western Programmes and ideas have been adopted by many Asian countries including Electronic Government (E-Government) program. In this era of digitization many countries around the world are developing digital information vigorously and implementing wired as well as wireless Service Delivery Programs (SDP). Various Asian countries are providing e-governance services to its citizens with the help of internet as also confirmed by a latest survey done by United Nations. There are various countries in the world but the authors have taken into account only certain neighboring countries of India. No doubt all the countries are trying their best to apply ICT for Governance for their citizens. Out of these three one country is China, which is most populated country of the world. The second populated country being the native country of authors has been taken into account. The third country being taken into consideration is the Pakistan, whose in the e-readiness score is far behind India and China. As per Economic Intelligence Unit (EIU) [12], Digital Economy Ranking 2010 beyond e-readiness, the status of these countries is China is at the $56^{\text {th }}$ place, India at $58^{\text {th }}$ place and Pakistan is at $66^{\text {th }}$ place and all the three countries have retained their position of the year 2009 ranking. The demographic status and status of ICT infrastructure of all these three countries in brief is as here.

\subsection{Indian portal \& E-Governance}

India is a country in South Asia. It is the seventh-largest country by geographical area, the second-most populous country with over 1.2 billion people, and the most populous democracy in the world. Total area of India is 32,87,263 sq. Km. Population density of India is 368 person per square kilometer. Type of Government in India is federal parliamentary and constitutional republic. As per 2011 census population of 
India is $1,210,193,422$. Population grew at $1.76 \%$ per annum during 2001-2011, down from $2.13 \%$ per annum in the previous decade (1991-2001). The human sex ratio, according to the 2011 census, is 940 females per 1,000 males. The literacy rate in 2011 was $73.8 \%$; $65.46 \%$ among females and $82.14 \%$ among males. Regarding infrastructural growth, growth of IT sector in India has been fuelled by equally impressive growth in telecommunication infrastructure. The world is moving towards converged networks being referred as 'Next Generation Networks (NGN)'. In the coming decade the NGN is likely to replace the legacy networks. This upcoming national information infrastructure would be marriage of IT and telecommunication infrastructure with various regulatory and security challenges that need careful scrutiny [15]. National Portal of India (NPI) is designed and developed by National Informatics Centre (NIC) which is Premier organization of Government of India (GOI) under the aegis of Department of Information Technology (DIT), Ministry of Communication and Information Technology (MCIT). NPI has been developed as Mission Mode project (MMP) under National e-Governance Plan of the Government. Major aim of the NPI is to provide single window access for providing information and services to its citizens. A try has been made to provide accurate, reliable and comprehensive information to the users through NPI. Content development of the portal is collective effort of various Indian Government ministries and various departments at Centre, state and various levels. Portal is maintained and updated on regular and enhancement and enrichment of the portal is going on improving day by day in terms of content, design and technology. Information related with the content, archival, review and contribution, maintenance and moderation is available on the portal itself. For maintaining standards and usability of users, NPI is designed using XHTML 1.0 and meets level AA of the Web Content Accessibility Guidelines (WCAG) 2.0 laid by the World wide web Consortium (W3C)[7]. For readability and ease in accessing the information on the portal Hindi version of the portal is available at http: \\ bharat.gov.in. Snap shot of NPI is shown in fig. 1 below.

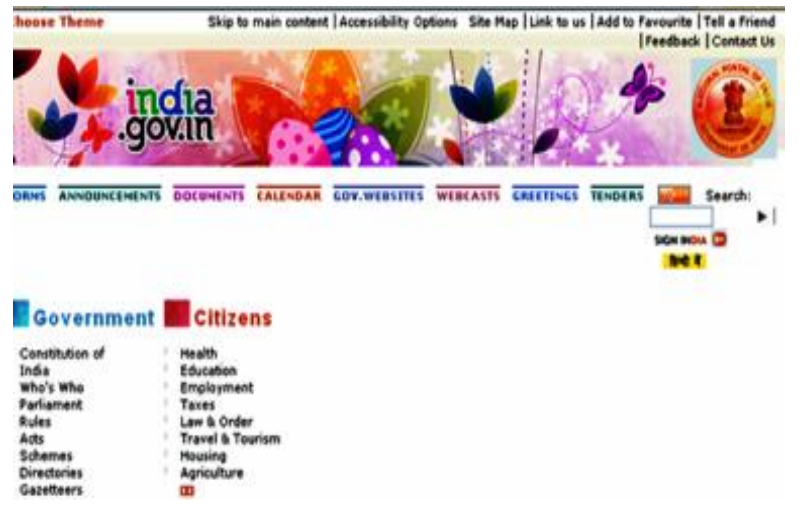

\subsection{Pakistan and its E-Government Programme}

Pakistan is a developing nation and with increased commercialization there is need to increase its e-service platform to all classes of citizens. In a survey done by the United Nations, Pakistan comes in mid range as far as its e- Government services are concerned. Survey [8] says that the most commonly used e-services by the citizens of Pakistan were education, job, utility bills, passport and taxation. It is also being observed that Citizens use Internet on regular basis which is good indicator of the increasing penetration of internet and computer services in Pakistan. In October 2002 the Electronic Government Directorate (EGD) was established in pursuance to a decision of the federal cabinet. EGD is a dedicated wing of Ministry of Information Technology. The Government of Pakistan (GOP) announced its E-Government Programme in 2005. Indeed, the E-Government Programme of Pakistan represents a paradigm shift for providing the services to its citizen but still much has to be incorporated in Pakistan's E-Government portal such as spatial information that is being developed as E-Government projects but is missing in the portal right now [10]. EGD has been established to perform the following functions

(1) Preparation of e-government projects.

(2) Implementation of federal level e-Government projects approved by government.

(3) Preparation of standards and guidelines.

(4) Providing technical support to the Federal, Provincial and District departments.

By applying this Programme Government aims to achieve certain objectives like improving service delivery to citizens and increasing internal efficiency of government operations of all departments of the government so that government functionaries become well versed in the use of ICT to provide service in a speedy, efficient and transparent governance. Certain barriers are still there in implementation of E-Governance in Pakistan . Some of these may include Infrastructure barriers, Regulatory barriers, Skilled personnel barriers, Security barriers and Social and cultural barriers [8]. Except these barriers one of the major barriers in development of e-Governance in Pakistan is the political instability due to which plans, strategies implemented by one government may not be continued by another Government. Moreover political stability plays a great role in the overall development of any country but E-governance field is mostly dependent on the Vision of Governments and its bureaucracy. The snap of the Pakistan Portal is here as fig. 2 below.

Figure 1. Snap shot of NPI; Source [7] 


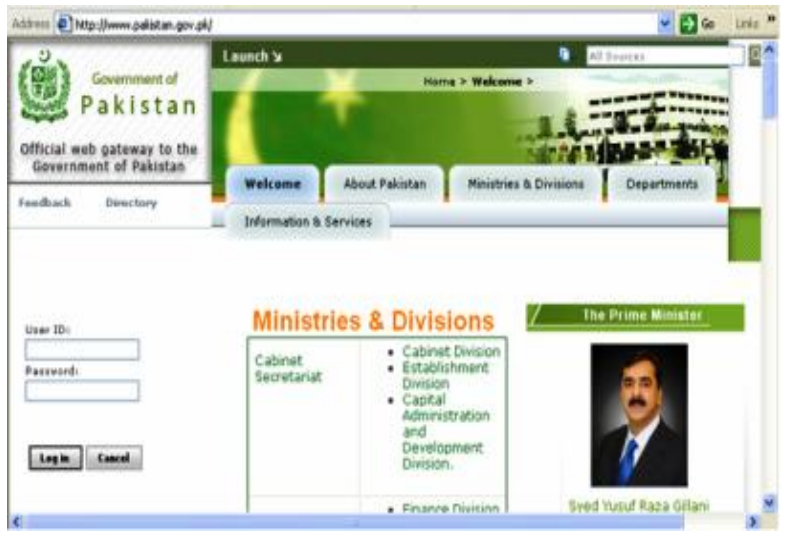

Figure. 2 Snap shot of the Pakistan Portal; Source[9]

\subsection{Pakistan and its E-Government Programme}

China is a country in East Asia. It is the second-largest country by geographical area, the most populous country with over 1.3 billion people, and the most populous democracy in the world.Being populous country in world, it has initiated certain step to stabilize population growth and is hoped that population growth in China will stabilize in the early decades of the 21 st century, though some projections estimate a population of anywhere between 1.4 billion and 1.6 billion by 2025 [17]. The People's Republic of China is a single-party state governed by the Communist Party of China. As of year 2007, 93.3\% of the population over age 15 are literate. In 2000, China's literacy rate among 15-to-24-year-old was 98.9\% (99.2\% for males and $98.5 \%$ for females) [17]. Regarding various e-governance initiatives in China, E-government began in the early 1980's through office automation. In 1993 the Government of China launched the 'Golden Project'. On 22 January, 1999 the Government Online Project (GOP) was officially launched. Main aim of GOP was to lay the foundation for China e-government development, facilitate G2G and $\mathrm{G} 2 \mathrm{C}$ communication at different levels. The Government of China has set up the National Informatisation Office (NIO) to promote the progress of ICT implementation. After this there was a lot of improvement in government websites in China. In 2003, the World Economic Forum (WEF) conducted a survey of national government websites to assess the quality and sophistication of their online services. In the final report, WEF classed China as being in the highest transaction stage, meaning that e-government in China is able to deliver electronic payments [13]. Snap shot of china portal is shown in fig. 3 below.

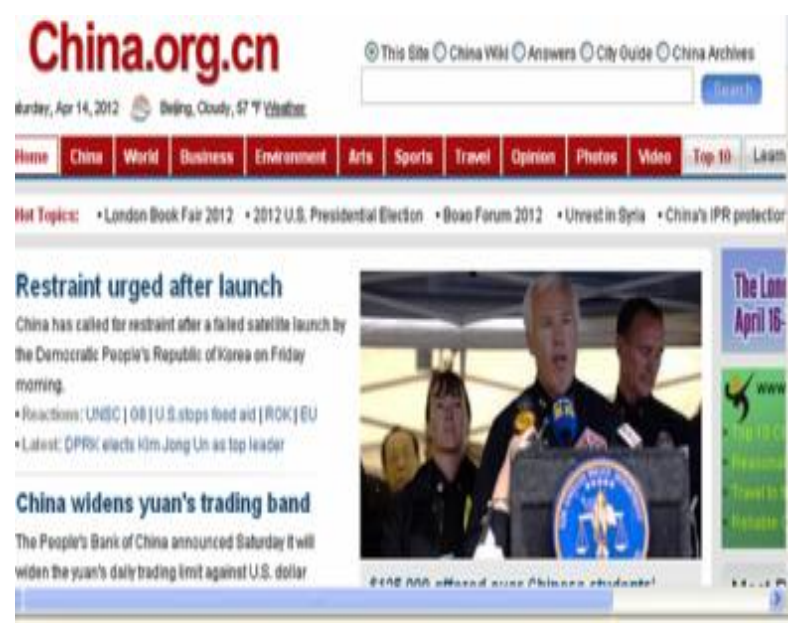

Figure. 3 snap shot of China portal; Source [11]

\section{ANALYSIS}

Services available on the Internet come in the category of Self-service technologies (SSTs). SSTs are technological interfaces that enable customers to produce a service independent of direct service employee involvement. Government information plays important role in the development of any nation .Being a basic right for each citizen, it is also duty of governments to avail relevant and timely information to its citizens for timely decision making. This is achievable through use of electronic media so as to have a balanced knowledgeable citizenship as well as an efficient and effective system of governance [14]. The parameters or metrics for the success of web portals of E-Government and E-commerce must be different. In case of E-commerce one is to take into consideration about the competition in the market whereas in e-governance services this is not the case as mainly services are to be provided by the Government itself being its duty. Hence all the metrics that are necessary for e-commerce need not necessarily be true in case of Government. But e-Governance portal should at least provide the basic qualities or metrics. Many e-governments are responsible for managing and organizing a variety of information. Therefore search function, functionality, and navigation are important for the execution of those Responsibilities .There are various performance measurement indicators widely used for evaluation of websites and web portal. Some of the indicators may be frequency of use of services, number of users, visitors, site hits, searchable option, accessibility, language option, performance, functionality, broken links, traffic analysis, feedback and many more. These three web portals will be analyzed in detail. Out of these above-mentioned indicators here, the authors have concentrated on the factors like traffic analysis, feedback, searchable option, language and accessibility, Content and citizen services. Accessibility has a key role in the development of the website. People with special needs must be taken into account while designing and developing a web portal. Accessibility can also be 
increased with the help of providing various language options and fonts. Web portal is group of various websites, that are linked on the home page of the portal. Each website has lot of information .If user/citizen wants to know about a information or service on a portal, then search option (if available) on the portal may be utilized. In the absence of such an option on a portal, it will be a time consuming process to find relevant information. Feedback option is also an important to know the ideas of viewers or users of the portal and its services. Many times very good suggestions are provided by the general public users or citizens. Because they are the ultimate users of the services and they know better what shortcomings are in the present system. By knowing the problems faced by citizens one can think of their solutions. Traffic analysis means how many people are using the web portal. This analysis is done on the basis of number of frequent users of the portal, total hits, frequency of use of services and visitors. Metrics used here are: Content, Usability, accessibility, privacy and security, general services, citizen participation and Traffic analysis.

\section{(1) Content}

Content is the major part of any portal. Informative content available on the portal is very crucial to the success of any portal. Content should neither be less nor more on the portal. It must have at least frequently needed information on it. Providing services to its citizens must be major aim of the portals basically in developing and populous countries. Because most of the problems in developing countries are due to the red-tapism and bureaucratic hurdles which give rise to other social evils like corruption and delay in providing services to its citizens in a transparent manner. Regarding content, NPI is devoted to its citizens and various types of services are available through this portal. Links of many other sub portals exist at the NPI for listening the grievances from various states and Centre departments and citizens. At NPI, more stress is laid on the citizen service which is necessary for democratic state like India. On the 'How do I' column at NPI, one can find valuable information, important links and various services provided by various Governments, that can be availed by citizens sitting at their homes. Pakistan portal has various links on the main page regarding languages, government and e-governance in Pakistan. Portal is divided in to 5 sections namely, about Pakistan, ministries and divisions, departments, information and services. About Pakistan part gives information about Pakistan and details of various other websites linked to the portal. Ministries and divisions give details about various departments and ministries of Pakistan. Various web links regarding various departments of Pakistan are available on the portal under heading departments. Employment information is available on this section. Feedback, directory and search options are also available on the portal. But Portal has no such column like providing online services to its citizens at the home page of the portal. By having a look at the sitemaps of both the portals it can be concluded that NPI has more information and services regarding use of its citizens. China portal has detailed information about china, world, weather, art, business, environment, sports, travel, opinion, photo, video, top 10 and learn Chinese languages. Top 10 features available on the portal give details of top 10 companies, richest people in china and on earth, cities, hotels, ancient cities and many more. Portal is full of content and pictures showing latest events in china and the world.

\section{(2) Usability}

It includes features like, home page and its length, overlapping of information on various links, user-friendly design, targeted audience links or channels, and site search capabilities. On these features National Portal of India (NPI) information is accessible to to people with disabilities using various assistive technologies like screen readers and magnifiers.Language option in case of China portal permits one to choose any language among various languages. This China portal provides more flexibility in selection of language to its citizens as compared to India and Pakistan. Ultimately language option increases the usability of the portal. China portal is much better because of length of the homepage is more as compared to other portals. It provides more flexibility in searching option available on the portal. Many language options are available on this portal as compared to other portals. China portal has link to learn Chinese language that may increase usability of the portal . User friendly nature of the portal can be known through knowing the number of users using the portal. For ease in using the portal Pakistan portal is having online dictionary regarding Urdu, Torwali and Sindhi English dictionary. But language option and contact us, site amp are not readily available on the Pakistan portal home page. NPI is having these features on its home page. In this category China portal is at top of the list then Indian portal and lastly the Pakistan portal is regarding usability feature of the portal.

\section{(3) Accessibility}

Accessibility option enables you to increase or decrease the font size and/or change color scheme of this website according to your preferences. One can change the text size and contrast of the portal. To Access information from any portal search option is also very helpful. Accessibility options and statements are available on the Indian portal. NPI can also be accessed by all users using various devices, technologies and abilities. NPI provides more accessibility and usability to its visitors and hence can be viewed from a variety of devices like mobile devices, PDAs, WAP phones and so on. Information on NPI is accessible to people with 
disabilities using various assistive technologies like screen readers and magnifiers. Search option is available on all these portals but China portal provides more flexibility in selection of options as compared to other portals. Pakistan portal is again lacking on this part.

\section{(4) Privacy and security}

Privacy and security include the features like Privacy policies, authentication, encryption, data management. Data available on the portal must be managed properly for its effective use by users of the portal. To access private information about citizens or governments certain checks must be there. This job is completed by providing various checks to access secure and private information. Hence providing user login and password is must to access to access such type of services and Information. NPI, Pakistan and China portals have login features for authentication and entering the secure area of these portals. To send information in a secured manner one of the foremost way is to send through encryption and then decrypt information at the target end. For authentication part one can use login details yet after providing these details information passed to others also should be in encrypted mode. To measure security of these portals there is requirement of certain tools like various vulnerability scanners and permissions from the developers and designers of the portals which is also not an easy job.

\section{(5) General services}

These services include whether feedback, language, search options are available on the portal or not. Through surveys one can measure the effectiveness of administrative actions of the Government towards its citizens. But if these surveys are done online that can help in measuring the effectiveness of the programs and through feedback options one can know the problems faced by the users of the services through the portals. Other factors which are included in the general services are transactional services involving purchase or register, interaction between citizens, businesses and government. Feedback option is not available on the China Portal yet it provides choices in use of languages. Various Search options are available on the China portal but it lacks on the part of feedback options. China portal has option for registration and sitemap but has no place for feedback option about the portal. Pakistan portal has no place for all these features except search option from all sources. Overall among all such features NPI is better than both the other portals.

\section{(6) General services}

Factors which constitute citizen participation include online citizen engagement, citizen services, Internet based policy deliberation, feedback and citizen based performance measurement. Feedback is one of the major contributors for citizen participation. Regarding citizen participation and feedback, every visitor is an important recipient of information. It is very important to get feedback from the visitor as much as possible. Special emphasis should be placed on systematic communication with current and potential users, analysis of user behavior and assessment of the site's user-friendliness by the agencies as well as effective communication of key information to users. Through feedback one can know about the problems, likes dislikes and other comments of citizens. Any query related to content, design, service and technological issues about NPI can be sent through customized feedback interface available at NPI. Pakistan and China portal has no place for feedback. For citizen engagement there is need to stress on providing more and more services online. Pakistan portal's link to information and services provide accurate information on government policies, Programmes, services and activities, with a view to generate public support for government policies, Programmes, services and activities, thereby creating the environment of mutual success. This section is dedicated to the management of information and services related to different departments of Pakistan. But one link 'Employment in Government Sector 'has only been shown on this portal. China portal does not have any direct link related to citizen services which is the one of the main motive of portals in populous countries. Whereas NPI under head 'How do I' provides ways to interact with citizens for various services.

\section{(7) Traffic Analysis}

Traffic analysis provides the details about popularity of the portal among users. By analyzing it one can have idea about the problems faced and use of online services by various types of visitors. One can know about the exact number of users of the portal month wise, which can help in the deciding the factors that increase the traffic. It is an important step as it shows the total impact of ICT in e-Governance on the citizens of a particular country. Hence traffic analysis must have some place on every portal. At NPI one can find monthly hit analysis that shows the visitors interest towards the portal from various states and countries. March 2012 summary from NPI shows that more than $66 \%$ of the users are from India and among Indian states. Delhi users (38\%) are highest. It shows hourly report about number of hits on the portal. This hourly report shows that during office hours it is gaining maximum hits [7]. Pakistan and China portal do not mention about checking of number of users. China portal stresses on areas like Home, China, world, business, environment, arts, sports, travel, opinion, photos, video, top10 and learning Chinese. Pakistan portal has main links to welcome, about Pakistan, Ministries and divisions, Departments and information and services. Certain links to various governments are also seen on the Pakistan portal but no place for visitors' 
summary is given on it. Both the portals of China and Pakistan have no place for checking the number of visitors on the portal

\section{CONCLUSIONS}

In the modern ICT world governments have no choice but to respond and adapt in order to remain effective and relevant towards needs of the citizens. By having a look on all these factors considered NPI comes to be the best of these three portals. China portal is better than Pakistan portal. Portals are built for citizen services and solutions of the problems faced by citizens through traditional system of governance. On this issue only Indian portal is providing direct link to such services on its homepage and both the other two portals lack of it. Users need reliable and timely information in this age of ICT. Reliability means protection of personal information and privacy, getting jobs done within the expected time frame and right from the first time, fast navigation in the web portal having no jams, availability of online-services on all days and at all time. The complete summary of various parameters for the evaluation of these web portals is shown here in table 1 below.

Table 1. Evaluation results for various web portals $[\sqrt{ }=$ yes \&

\begin{tabular}{|l|l|l|l|}
\hline $\begin{array}{l}\text { Evaluation } \\
\text { Parameters }\end{array}$ & China & India & Pakistan \\
\hline Content & $\sqrt{ }$ & $\sqrt{ }$ & $\times$ \\
\hline Usability & $\sqrt{ }$ & $\sqrt{ }$ & $\times$ \\
\hline Accessibility \& & $\sqrt{ }$ & $\sqrt{ }$ & $\times$ \\
\hline $\begin{array}{l}\text { Privacy } \\
\text { Security }\end{array}$ & $\sqrt{ }$ & $\sqrt{ }$ \\
\hline General Services & $\times$ & $\sqrt{ }$ & $\times$ \\
\hline $\begin{array}{l}\text { Citizen } \\
\text { Participation }\end{array}$ & $\times$ & $\sqrt{ }$ & $\times$ \\
\hline Visitors summary & $\times$ & $\sqrt{ }$ & $\times$ \\
\hline
\end{tabular}

For proper implementation of e-Governance projects there is need of a holistic approach to understand citizen needs and to fulfill their needs with the help of available technology and infrastructure by the governments and its stakeholders. Due to lack of it there are more chances of failures of e-Governance projects in developing countries.

\section{REFERENCES}

[1]Marjit Ujjal, Roy Ratan, Santra Subhranshu,Biswas Utpal ," A Semantic web service based Approach to E-Governance" IEEE Xplore, ACM Journal, Downloaded on October 21,2009 .
[2] Available at www.i4donline.net, NovemberDecember 2003

[3] Holzer Marc and Manoharan Aroon ," Global Trends in Municipal E-Government: An Online Assessment of Worldwide Municipal Web Portals" , Pp 178-188, Foundations of E-government , CSI Publication (2008).

[4] Agrawal Anand, Shah Pragya and Wadhwa Varun ,'EGOSQ - Users' Assessment of e-Governance Online-Services: A Quality Measurement Instrumentation", Foundations of E-government ,Pp 231-244, CSI publication (2008).

[5] "e-Governance: International Scenario", Promoting e-Governance - The SMART Way Forward, ARC_1 $11^{\text {th }}$ report.

[6] Arfeen Muhammad Irfanullah ," Impact of e-governance on the economy of Pakistan - the revolutionary plan ",Pakistan society of development economists (2004)

[7] Avaialble at www. India.gov.in

[8 Kayani Muhammad Bilal, Ehsan ul Haq M, Perwez M. Raza, Humayun Hasan," Analyzing Barriers in e-Government Implementation in Pakistan “,International Journal for Infonomics (IJI), Pp 494-500, Volume 4, Issue 3/4, September/December 2011.

[9] Avaialble at www.pakistan.gov.pk

[10] Ali Asmat," How Does NSDI Development Fit into Pakistan's E-Government Programme?" , Available at www.gsdi.org

[11] Available at www.china.org.cn

[12] Avaialble at www.graphics.eiu.com

[13] Guanghua Luo ," e-government, people and social change: a case study in china", The Electronic Journal on Information Systems in Developing Countries (EJISDC) Pp 1-23, Volume 38 Issue 3, (2009)

[14] Patel Adarsh, Vora Bhrantav," Impact Assessment Study on e-Governance Projects in Gujarat", Pp 98-102, IFRSA Business Review ,Vol2 ,issue 1,March 2012.

[15] Chaturvedi, MM.,Gupta, MP. and Bhattacharya, J.,"Cyber Security Infrastructure in India: A Study", Emerging Technologies in E-Government', CSI Publication (2008).

[16] Chander Subhash, Kush Ashwani," Performance evaluation of e-governance web portals", Pp 23-28, CSI Communications, March (2010).

[17] Available at www. en.wikipedia.org

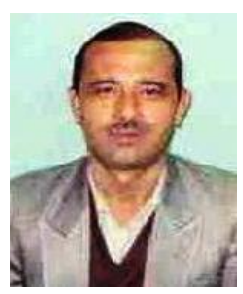

Subhash Chander: has been working as Assistant Professor in Govt. P.G. College, Karnal Haryana (India). He is a member of Computer Society of India (CSI) and Internet Society (ISOC). He has been a resource person for the Edusat programme of Haryana Govt. for college students since its inception. He has published more than fifteen papers in various Journals and National and International 
Conferences. The author's major fields of study include ICT, e-governance and security. Author can be contacted at subhashjaglan@gmail.com

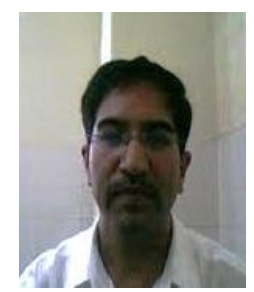

Dr. Kush: has been working as Associate Professor in Computer Science Department of University College, Kurukshetra University, Kurukshetra, Haryana (India). He is member of CSI, IEEE, IAENG, IJCSA. He has published more than 100 papers in various Journals and Conferences in India and abroad. His major fields of study include Mobile Adhoc Network (MANet), Security, e-governance. Author can be contacted at akush20@gmail.com 